Article

\title{
The Effects of Incorporated Sn in Resynthesized Ni-Rich Cathode Materials on Their Lithium-Ion Battery Performance
}

\author{
Ga-hee Kang ${ }^{1,2}$, Ko-woon Lee ${ }^{2}$, Kyungjung Kwon ${ }^{1, *} \mathbb{D}$ and Junho Song ${ }^{2, *}$ \\ 1 Department of Energy \& Mineral Resources Engineering, Sejong University, 209 Neungdong-ro, \\ Gwangjin-gu, Seoul 05006, Korea; energyre@naver.com \\ 2 Korea Electronics Technology Institute, 25 Saenari-ro, Bundang-gu, Seongnam-si, Gyeonggi-do 13509, \\ Korea; lgn882000@naver.com \\ * $\quad$ Correspondence: kfromberk@gmail.com (K.K.); junesong@keti.re.kr (J.S.); Tel.: +82-2-3408-3947 (K.K.)
}

Received: 29 August 2017; Accepted: 21 September 2017; Published: 26 September 2017

\begin{abstract}
LiNi}_{\mathrm{x}} \mathrm{Co}_{\mathrm{y}} \mathrm{Mn}_{\mathrm{z}}(\mathrm{NCM})$, one of the most promising candidates for high-capacity cathode materials in Li-ion batteries (LIBs), is synthesized with various amounts of Sn. Sn-incorporated NCM from the resynthesis of NMC in leach liquor containing Sn from spent LIBs is characterized by scanning electron microscopy, energy-dispersive X-ray spectroscopy, $\mathrm{X}$-ray diffraction, $\mathrm{X}$-ray photoelectron spectroscopy, particle strength tests, and electrochemical tests. Sn-incorporated NCM has a globular form, and the uniform distribution of $\mathrm{Sn}$ inside cathode materials is confirmed. As Sn is introduced, the (003) diffraction peak tends to shift to a smaller angle and particle breaking strength increases. It is found that $\mathrm{Sn}$-incorporated cathode active materials have better cycle performance and rate capability than pristine cathode active material although the discharge capacity slightly decreases. Because there is a trade-off between decreased discharge capacity and improved cycling and rate performance, the incorporation of $\mathrm{Sn}$ in resynthesized NCM should be carefully designed and conducted.
\end{abstract}

Keywords: lithium-ion battery; cathode; recycling; Sn

\section{Introduction}

Li-ion batteries (LIBs) are the most popular type of rechargeable batteries, as they have high energy, high power density, low memory effect, and low self-discharge rate [1]. The usage of LIBs has remarkably extended to electrical appliances, portable electronics, electric vehicles, and power grids [2]. Accordingly, a large number of spent LIBs have surely been generated due to their limited life spans and the rapid rate at which electronic products are updated [3].

In general, an LIB is composed of an anode (e.g., graphite, tin, and silicon), a cathode (e.g., $\mathrm{LiCoO}_{2}$, $\mathrm{LiMn}_{2} \mathrm{O}_{4}$, and $\mathrm{LiNi}_{\mathrm{x}} \mathrm{Co}_{\mathrm{y}} \mathrm{Mn}_{\mathrm{z}} \mathrm{O}_{2}(\mathrm{NCM})$ ), current collectors, an organic electrolyte with Li-containing salts, and a separator [4,5]. When spent LIBs are disposed of in a landfill or burned, heavy metals seep into groundwater, and a large volume of poisonous gas is generated. This situation could result in long-term environmental and public health problems [6]. Moreover, spent LIBs contain valuable metals such as cobalt, nickel, manganese, and lithium. Therefore, the recycling of spent LIBs could bring economic profits as well as environmental benefits [7]. Various techniques for recycling spent LIBs have been suggested in several papers [8-10]. Above all, the hydrometallurgical process is the most well-established technology for recycling valuable metals from LIBs and has many benefits, such as the complete recovery of metals with high purity, low energy consumption, and low gas emission [11-13]. Metal species of spent LIBs are typically leached by $\mathrm{HCl}, \mathrm{HNO}_{3}$, or $\mathrm{H}_{2} \mathrm{SO}_{4}$, with hydrogen peroxide used as a reducing agent in many cases [14-17]. Most metal species are expected 
to dissolve with acidic leaching reagents. Tin from anodes also dissolves with cathode metal species during the leaching process.

Cathode active materials such as NCM can be resynthesized from the leach liquor of spent LIBs by the co-precipitation method. The effect of impurities in resynthesized LIB cathode active materials on their electrochemical performance needs to be studied. The effect of $\mathrm{Mg}$ or $\mathrm{Al}$ impurities in leach liquor from spent LIBs on the electrochemical performance of resynthesized cathode active materials has been investigated $[18,19]$. However, there has been no study on the effect of $\mathrm{Sn}$ impurity on the LIB performance of resynthesized Ni-rich NCM, which has been highlighted as the most promising candidate for high-capacity cathode materials in LIBs due to their high energy density $[20,21]$. In this paper, we synthesized NCM with various amounts of Sn, simulating the resynthesis of NMC in leach liquor containing Sn from spent LIBs, and the effect of Sn on the LIB performance of NCM was investigated.

\section{Materials and Methods}

\subsection{Synthesis of Materials}

Precursors $\left(\mathrm{Ni}_{0.82} \mathrm{Co}_{0.12} \mathrm{Mn}_{0.06}(\mathrm{OH})_{2}\right)$ were synthesized by the hydroxide co-precipitation method, which is widely used to produce homogeneous compounds. A mixture of chelating agent $\left(\mathrm{NH}_{4} \mathrm{OH}\right)$, $\mathrm{NaOH}$ solution, and aqueous solutions of transition metal salts was pumped into a continuously stirred tank reactor. The resultant precursor slurry was filtered and washed multiple times, and then dried in an oven at $80{ }^{\circ} \mathrm{C}$. Tin was incorporated by mixing dried precursors $\left(\mathrm{Ni}_{0.82} \mathrm{Co}_{0.12} \mathrm{Mn}_{0.06}(\mathrm{OH})_{2}, 10 \mathrm{~g}\right)$ and tin(II) ethoxide $(0.05 \mathrm{~g}, 0.1 \mathrm{~g}, 0.15 \mathrm{~g}$, and $0.3 \mathrm{~g})$ in isopropyl alcohol $(100 \mathrm{~mL})$ at $60^{\circ} \mathrm{C}$. The final Ni-rich cathode active materials $\left(\mathrm{Li}\left[\mathrm{Ni}_{0.82} \mathrm{Co}_{0.12} \mathrm{Mn}_{0.06}\right]_{1-x} \mathrm{Sn}_{x} \mathrm{O}_{2}(x=0,0.004,0.008,0.012,0.024)\right)$ were prepared by calcinating a mixture of $\mathrm{Sn}$-incorporated precursors and the stoichiometric amount of $\mathrm{LiOH}$ at $800{ }^{\circ} \mathrm{C}$ (heating rate: $3^{\circ} \mathrm{C} \mathrm{min}^{-1}$ ) in an $\mathrm{O}_{2}$ atmosphere for $24 \mathrm{~h}$. Hereinafter, we denote the cathode active materials by their $\mathrm{Sn} w \mathrm{w} \%$. Namely, we refer to $\mathrm{Li}\left[\mathrm{Ni}_{0.82} \mathrm{Co}_{0.12} \mathrm{Mn}_{0.06}\right]_{1-x} \mathrm{Sn}_{x} \mathrm{O}_{2}(x=0$, $0.004,0.008,0.012,0.024)$ as pristine, Sn $0.5 \mathrm{wt} \%$, Sn $1.0 \mathrm{wt} \%$, Sn $1.5 \mathrm{wt} \%$, and Sn $3.0 \mathrm{wt} \%$, respectively. The synthesis procedure is summarized in Scheme 1.

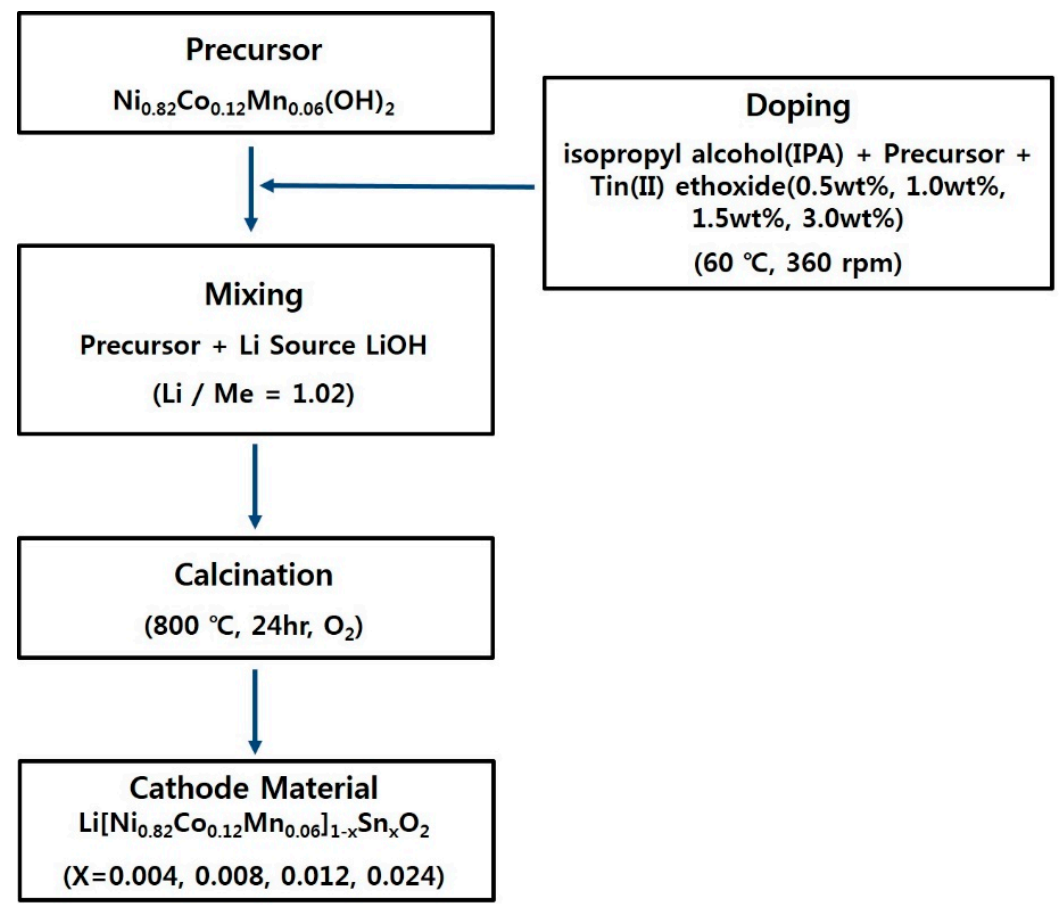

Scheme 1. The synthesis procedure of the cathode active materials. 


\subsection{Physicochemical and Electrochemical Characterizations}

The crystal structure of samples was obtained by X-ray diffraction (XRD, Panalytical Emprean, Eindhoven, The Netherlands). The particle morphology of samples was observed using a scanning electron microscope (SEM, JSM-6380, JEOL Ltd., Tokyo, Japan) and energy dispersive X-ray spectroscopy (EDS, JEM 2300, Oxford Ltd., Abingdon, UK). The combined bond state of samples was obtained using X-ray photoelectron spectra (XPS, K-alpha, Thermo, Waltham, MA, USA). The particle hardness of samples was measured using a particle compression tester (PCT, MCT-W500-EGA, Shimadzu, Kyoto, Japan).

Charge-discharge tests were performed using CR2032-type coin cells. Cathodes were prepared by mixing the cathode active materials, carbon black (Super-P), and polyvinylidene fluoride (KF1100) binder in a mass ratio of 95:2:3 respectively. Cells were assembled with the prepared cathodes, lithium metal as an anode, polyethylene film as a separator, and $1 \mathrm{M} \mathrm{LiPF}_{6}$ in a mixture of ethylene carbonate and ethyl methyl carbonate (1:2, volume ratio) as an electrolyte. The cells were cycled from 3.0 to 4.3 , 4.4 , or $4.5 \mathrm{~V}$ (vs. $\left.\mathrm{Li} / \mathrm{Li}^{+}\right)$at different C-rates at room temperature or at a high temperature $\left(60{ }^{\circ} \mathrm{C}\right)$. Unless stated otherwise, potential values are based on $\mathrm{Li} / \mathrm{Li}^{+}$potential.

\section{Results and Discussion}

\subsection{Physicochemical Characterizations of Sn-Incorporated Ni-Rich Cathode Active Materials}

The SEM images in Figure 1 show the morphology of the Sn-incorporated precursors and the cathode active materials. The secondary particles of the precursors seem to have a quasi-spherical shape, and each secondary particle is an agglomerate of fine acicular primary particles. Similarly, the secondary particles of the cathode active materials have a quasi-spherical shape, and each secondary particle is an agglomerate of granular primary particles, which are thicker than those of the precursors. The average secondary particle sizes of the precursors and the cathode active materials are similar at around $9 \mu \mathrm{m}$. There is no distinct correlation between the secondary particle size and the Sn content. Incidentally, Figure S1 represents the cross section of the cathode active materials indicating that the Sn content would not affect the compactness of particles. The distribution of elements in the cathode active materials was looked into by using EDS mapping. Figure 2, which shows the results of the EDS mapping for Sn $3.0 \mathrm{wt} \%$, is a representative result indicating the homogeneous distribution of $\mathrm{Ni}, \mathrm{Co}$, $\mathrm{Mn}$, and Sn. The EDS cross-section mapping of the pristine, Sn $0.5 \mathrm{wt} \%$, Sn $1.0 \mathrm{wt} \%$, and Sn $1.5 \mathrm{wt} \%$ samples is displayed in Figure S2.

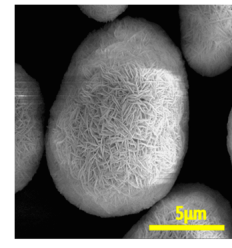

(a)

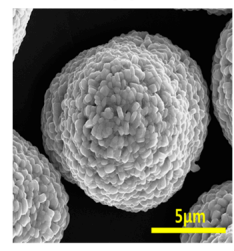

(f)

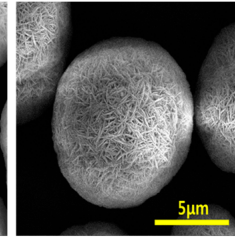

(b)

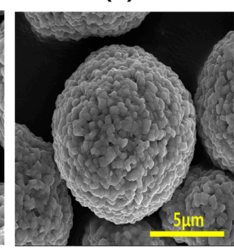

(g)

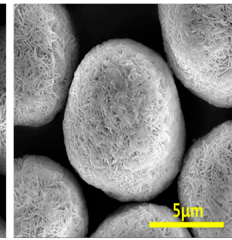

(c)

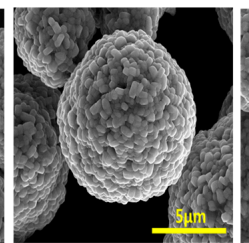

(h)

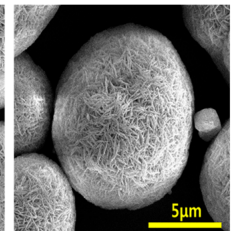

(d)

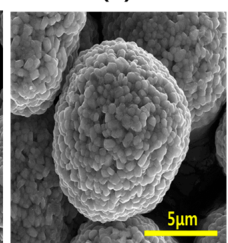

(i)

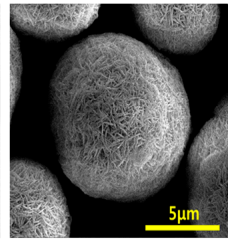

(e)

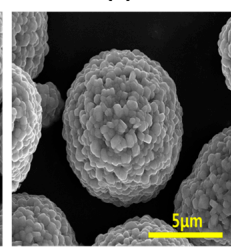

(j)

Figure 1. SEM images of the Sn-incorporated precursors ((a) pristine, (b) Sn $0.5 \mathrm{wt} \%$, (c) Sn $1.0 \mathrm{wt} \%$, (d) Sn $1.5 \mathrm{wt} \%$, and (e) Sn $3.0 \mathrm{wt} \%$ ) and the cathode active materials ((f) pristine, (g) Sn $0.5 \mathrm{wt} \%$, (h) Sn $1.0 \mathrm{wt} \%$, (i) Sn $1.5 \mathrm{wt} \%$, and (j) Sn $3.0 \mathrm{wt} \%$ ). 

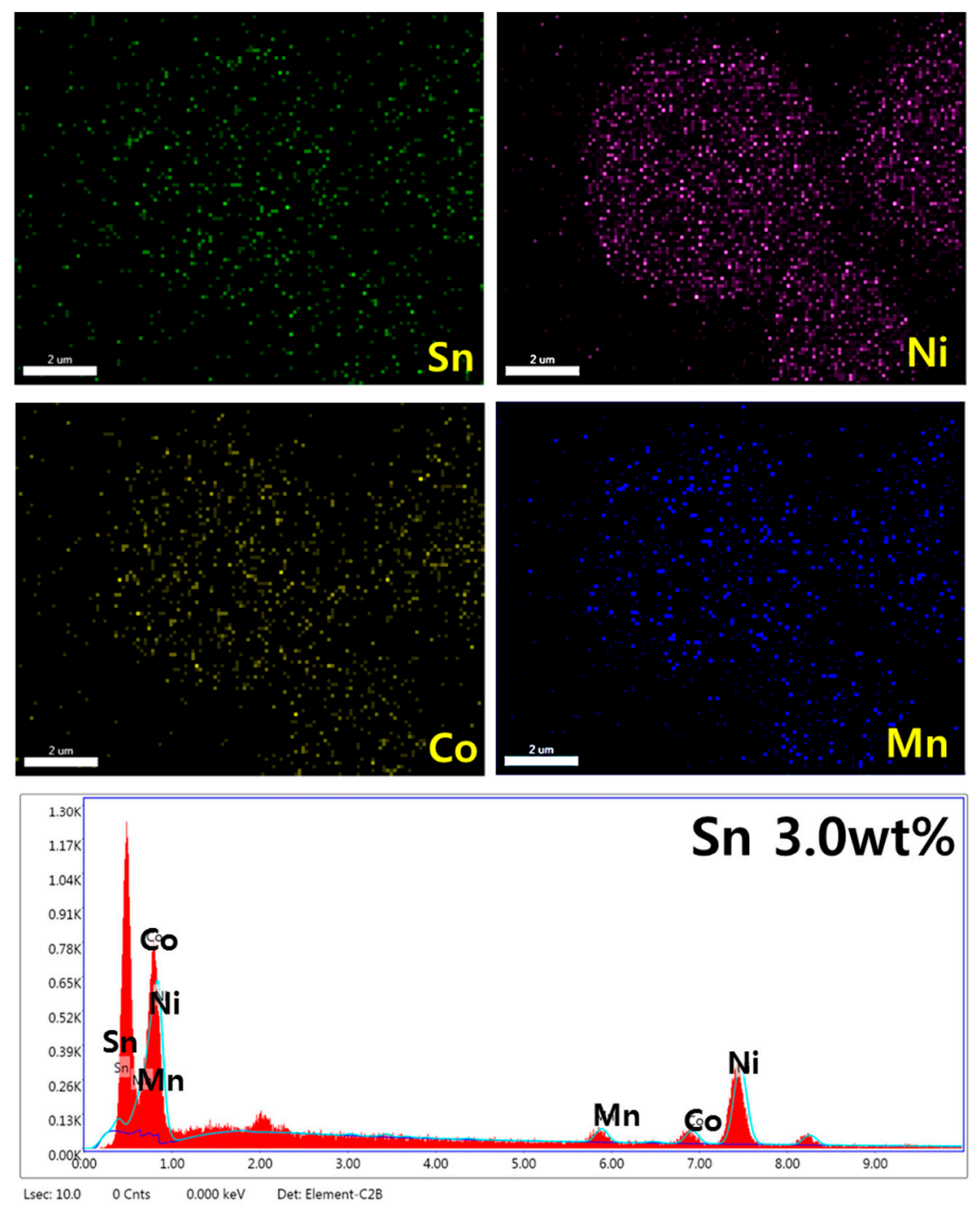

Figure 2. EDS (energy dispersive X-ray spectroscopy) cross-section mapping of the $\mathrm{Sn} 3.0 \mathrm{wt} \%$ cathode active materials.

The crystal structures of the cathode active materials were characterized using XRD as shown in Figure 3a. Two representative peak splitting doublets, (006)/(102) and (108)/(110), were clearly observed, which indicates that a well-ordered layered structure was constructed during the calcination process [22]. In addition, no peaks other than $\mathrm{Li}\left[\mathrm{Ni}_{0.82} \mathrm{Co}_{0.12} \mathrm{Mn}_{0.06}\right]_{2}$ were observed even when no less than $3.0 \mathrm{wt} \% \mathrm{Sn}$ was introduced to the pristine sample, which would mean that all Sn atoms were incorporated into the crystal structure of $\mathrm{Li}\left[\mathrm{Ni}_{0.82} \mathrm{Co}_{0.12} \mathrm{Mn}_{0.06}\right] \mathrm{O}_{2}$ without forming secondary phases. Figure $3 \mathrm{~b}$ shows the magnified (003) peak region in the $2 \theta$ around $19^{\circ}$. The peak tends to shift toward lower angles with the Sn content, suggesting an expanded d-spacing according to Bragg's law. This peak shift is in line with increases in lattice parameters in $a$ - and $c$-directions with increasing the Sn content, as shown in Table 1 . These structural characteristics can be explained by a larger ionic radius of $\mathrm{Sn}^{4+}(0.71 \AA)$ than that of $\mathrm{Co}^{3+}(0.62 \AA), \mathrm{Ni}^{2+}(0.69 \AA), \mathrm{Ni}^{3+}(0.56 \AA)$, and $\mathrm{Mn}^{4+}(0.53 \AA)$ [23]. Incidentally, the peak shift and the corresponding lattice expansion are not proportional to the $\mathrm{Sn}$ content beyond $1.0 \mathrm{wt} \%$, the origin of which is not clear at this stage. There is a possibility of $\mathrm{SnO}_{2}$ formation in adding Sn higher than $1.5 \mathrm{wt} \%$ to $\mathrm{Li}\left[\mathrm{Ni}_{0.82} \mathrm{Co}_{0.12} \mathrm{Mn}_{0.06}\right] \mathrm{O}_{2}$ although we did not observe any tangible XRD peak for $\mathrm{SnO}_{2}$ [23]. However, the $\mathrm{Sn}$ content in NCM was measured by inductively coupled plasma mass spectrometry, which showed that $\mathrm{Li}\left[\mathrm{Ni}_{0.82} \mathrm{Co}_{0.12} \mathrm{Mn}_{0.06}\right]_{1-x} \mathrm{Sn}_{x} \mathrm{O}_{2}$ contains the designed value of Sn up to $3.0 \mathrm{wt} \%$. 


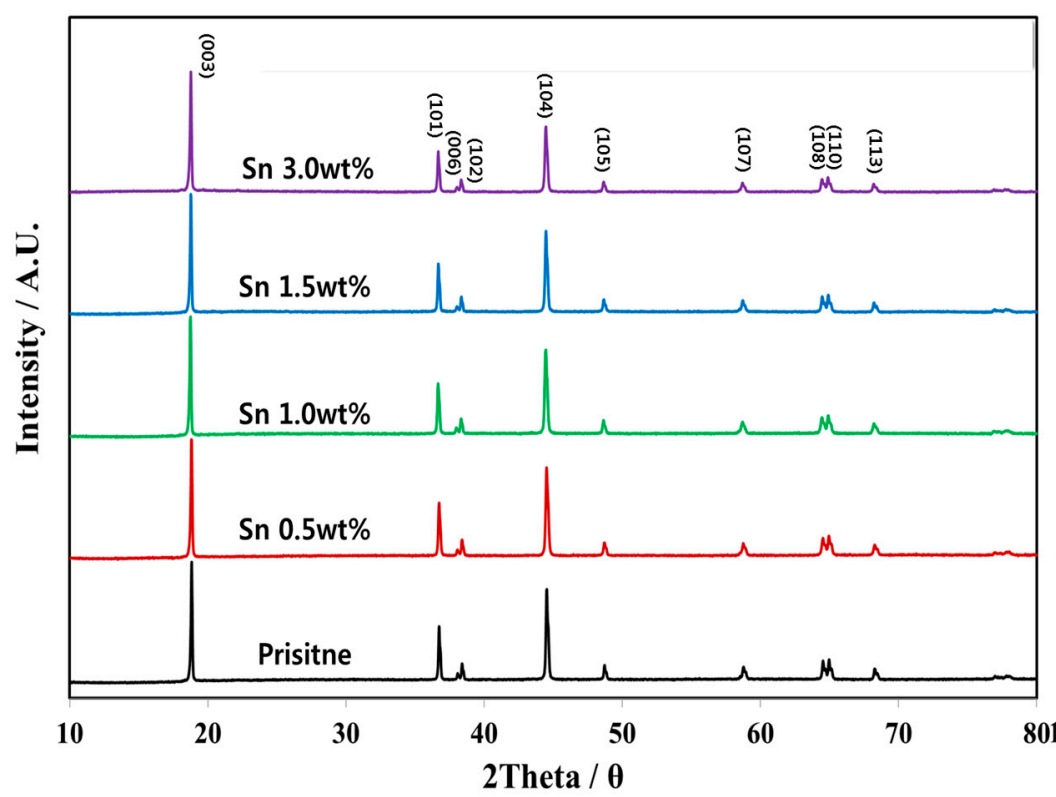

(a)

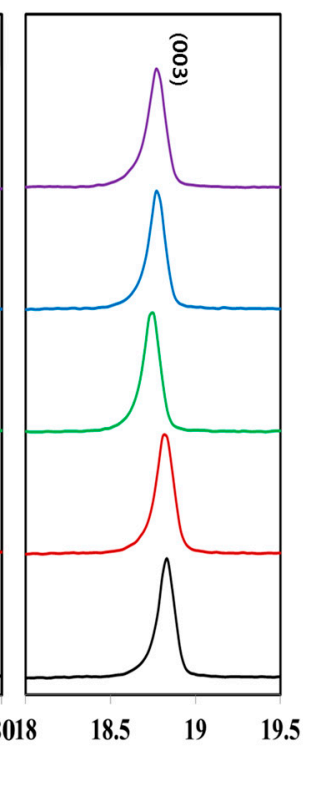

(b)

Figure 3. XRD patterns of the cathode active materials: (a) full spectrum and (b) expanded view around (003).

Table 1. Lattice parameters of the cathode active materials.

\begin{tabular}{cccccc}
\hline Lattice Parameter & Pristine & Sn $\mathbf{0 . 5} \mathbf{~ w t} \%$ & Sn $\mathbf{1 . 0} \mathbf{w t} \%$ & Sn $\mathbf{1 . 5} \mathbf{w t} \%$ & Sn $\mathbf{3 . 0} \mathbf{w t} \%$ \\
\hline$a[\AA]$ & 2.86769 & 2.86794 & 2.87031 & 2.87007 & 2.86819 \\
$c[\AA]$ & 14.13716 & 14.14405 & 14.19612 & 14.17667 & 14.14698 \\
\hline
\end{tabular}

In order to investigate the oxidation states of nickel, cobalt, manganese, and tin, an XPS measurement was performed. The wide scan spectrum indicates the presence of $\mathrm{Co}, \mathrm{Ni}, \mathrm{Mn}, \mathrm{O}$, and Sn (Figure S3). Figure 4 shows that the binding energies of $\mathrm{Co}, \mathrm{Ni}, \mathrm{Mn}$, and $\mathrm{Sn}$ belong to $\mathrm{Co}^{3+}$, $\mathrm{Ni}^{2+}, \mathrm{Ni}^{3+}, \mathrm{Mn}^{4+}$, and $\mathrm{Sn}^{4+}$. The $\mathrm{Co} 2 \mathrm{p}$ spectrum has two main peaks of $2 \mathrm{p}_{3 / 2}$ at $780 \mathrm{eV}$ and $2 \mathrm{p}_{1 / 2}$ at $795 \mathrm{eV}$. For Ni 2p, 2 $\mathrm{p}_{3 / 2}$, and $2 \mathrm{p}_{1 / 2}$ are located at $854 \mathrm{eV}$ and $872 \mathrm{eV}$, respectively. While the main peaks of Mn $2 \mathrm{p}$ are $2 \mathrm{p}_{3 / 2}$ at $642 \mathrm{eV}$ and $2 \mathrm{p}_{1 / 2}$ at $653 \mathrm{eV}$, the peak position of $\mathrm{Sn} 3 \mathrm{~d}_{5 / 2}$ and $3 \mathrm{~d}_{3 / 2}$ is $486 \mathrm{eV}$ and $494 \mathrm{eV}$, which would represent the $\mathrm{Sn}^{4+}$ cations [22,24]. In the $\mathrm{O}$ 1s spectra, two peaks are observed characteristic of $\mathrm{O}^{2-}$ anions belonging to the crystalline network and weakly absorbed surface species [25].

The breaking strength of cathode active material particles depending on the Sn content was measured as in Table 2. When an indenter of particle compression tester applies force to a particle in the vertical direction, the breaking strength is calculated at breaking point using two parameters as follows:

$$
\sigma_{\mathrm{t}}=\frac{2.8 P}{\pi D^{2}}
$$

where $\sigma_{\mathrm{t}}$ is the breaking strength, $P$ is the force at breaking point, and $D$ is the diameter of the particle. The breaking strength of the Sn-incorporated samples in Table 2 is higher than the pristine sample, and the highest breaking strength was observed at Sn $1.0 \mathrm{wt} \%$. Cathode active material particles that have high breaking strength are expected to show excellent cycleability because high breaking strength restrains structural deformation, particularly at a high voltage and high C-rate [26,27]. 

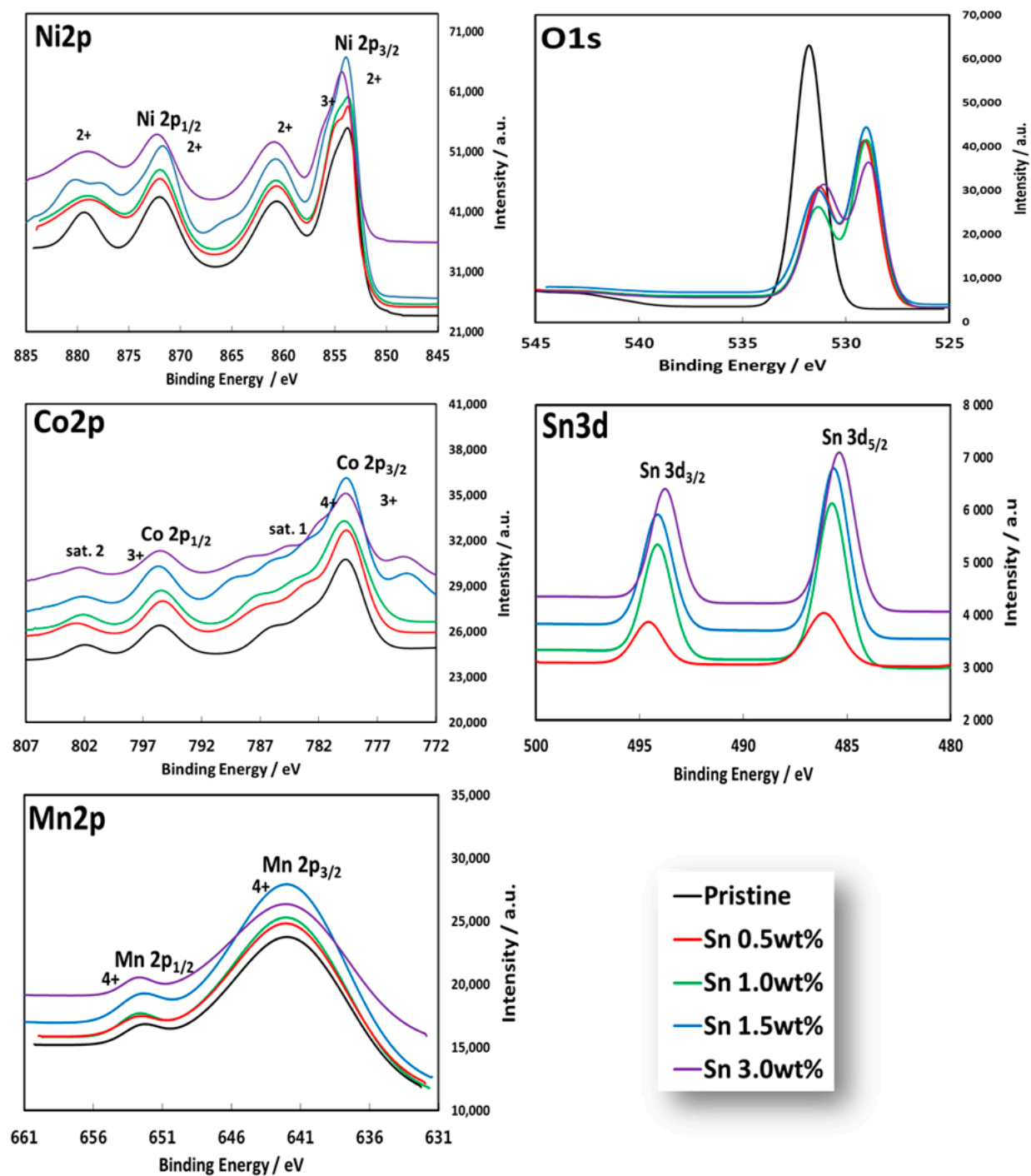

Figure 4. XPS of the cathode active materials.

Table 2. Breaking strength of the cathode active material particles.

\begin{tabular}{cccc}
\hline Sample & Force $\boldsymbol{P}(\mathbf{m N})$ & Diameter $\boldsymbol{D}(\boldsymbol{\mu m})$ & $\left.\boldsymbol{\sigma}_{\mathbf{t}} \mathbf{( M P a}\right)$ \\
\hline Pristine & 8.29 & 9.39 & 83.86 \\
Sn 0.5 wt $\%$ & 12.12 & 9.87 & 110.98 \\
Sn 1.0 wt $\%$ & 12.34 & 8.91 & 138.49 \\
Sn 1.5 wt $\%$ & 13.75 & 11.47 & 93.16 \\
Sn 3.0 wt $\%$ & 10.52 & 10.24 & 89.43 \\
\hline
\end{tabular}

\subsection{Electrochemical Characterizations of Sn-Incorporated Ni-Rich Cathode Active Materials}

Figure 5 shows the first charge-discharge profiles of the cathode active materials at a constant current density of $0.1 \mathrm{C}$ between 3.0 and $4.3 \mathrm{~V}$ at room temperature. As shown in Table 3, the discharge capacity of the Sn-incorporated cathode active materials is slightly decreased compared to the pristine cathode active material because $\mathrm{Sn}^{4+}$ is inactive during the charge-discharge process.

To evaluate rate performance, the cathode active materials were tested at various $C$-rates between 3.0 and $4.3 \mathrm{~V}$, and their discharge capacities are presented in Figure 6. The Sn-incorporated cathode active materials have higher discharge capacities (Sn $0.5 \mathrm{wt} \%: 126.65 \mathrm{mAh} \mathrm{g}^{-1}$, Sn $1.0 \mathrm{wt} \%$ : $148.98 \mathrm{mAh} \mathrm{g}^{-1}$, Sn $1.5 \mathrm{wt} \%: 147.90 \mathrm{mAh} \mathrm{g}^{-1}$, and Sn $3.0 \mathrm{wt} \%: 147.61 \mathrm{mAh} \mathrm{g}^{-1}$ ) than the pristine 
cathode active material $\left(116.80 \mathrm{mAh} \mathrm{g}^{-1}\right)$ at $5 \mathrm{C}$. It is noticeable that the Sn-incorporated cathode active materials have low overpotential compared to the pristine cathode active material at $5 \mathrm{C}$ (Figure 7). Incorporated Sn could reduce polarization at the interface between the cathode and electrolyte [25]. As previously mentioned, incorporated $\mathrm{Sn}^{4+}$ ions that have a larger ionic radius than other ions allow lattice volume expansion, which enhances $\mathrm{Li}^{+}$intercalation/deintercalation.

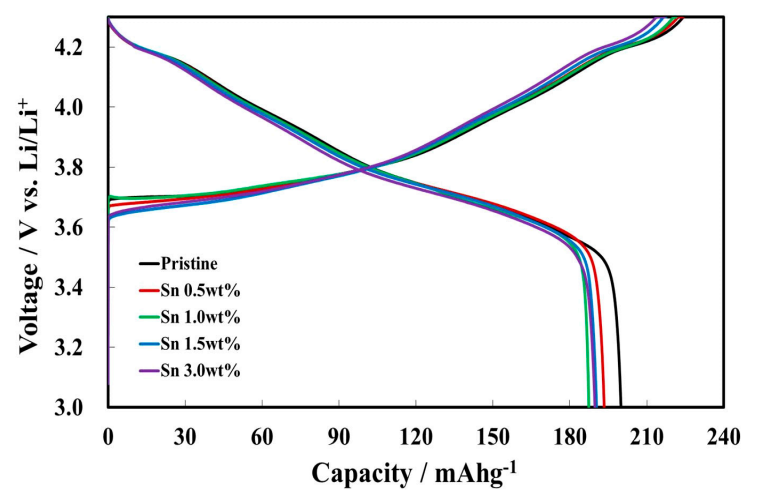

Figure 5. Initial charge-discharge profiles of the cathode active materials.

Table 3. Initial charge-discharge capacity of the cathode active materials.

\begin{tabular}{ccc}
\hline Sample & Charge $\left(\mathbf{m A h ~} \mathbf{g}^{\mathbf{- 1}}\right)$ & Discharge $\left(\mathbf{m} \mathbf{A h} \mathbf{g}^{\mathbf{- 1}}\right)$ \\
\hline Pristine & 225.98 & 199.92 \\
Sn 0.5 wt \% & 224.03 & 193.38 \\
Sn 1.0 wt \% & 221.39 & 187.39 \\
Sn 1.5 wt \% & 217.43 & 190.38 \\
Sn 3.0 wt \% & 216.80 & 189.74 \\
\hline
\end{tabular}

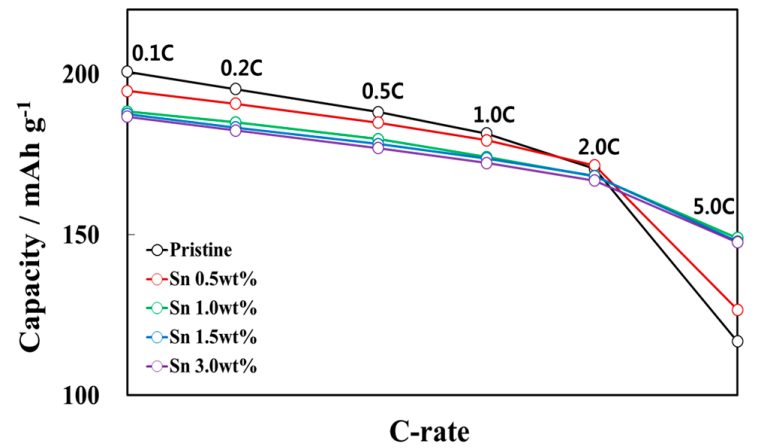

Figure 6. Discharge capacity of the cathode active materials at $0.1 \mathrm{C}, 0.2 \mathrm{C}, 0.5 \mathrm{C}, 1 \mathrm{C}, 2 \mathrm{C}$, and $5 \mathrm{C}$.

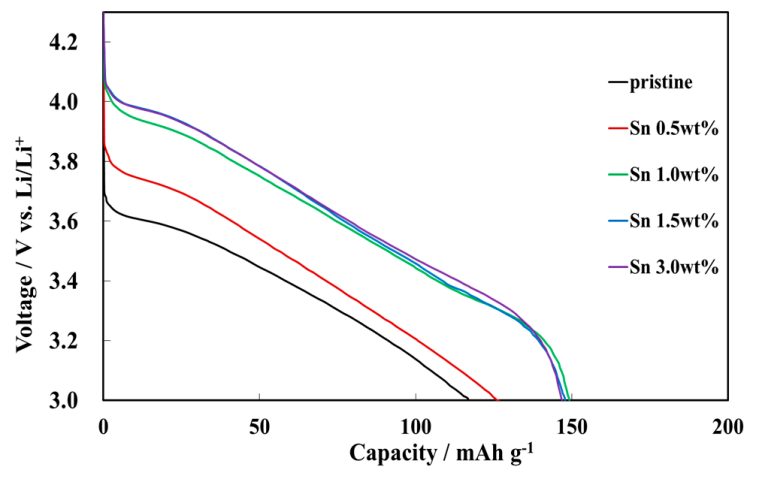

Figure 7. Discharge profile of the cathode active materials at $5 \mathrm{C}$. 
As mentioned previously in Table 2, the cycleability of the Sn-incorporated samples is expected to be superior to that of the pristine sample. Accordingly, the cycleability of the cathode active materials under various conditions was investigated in Figure 8 (to 4.3/4.4/4.5 V at room temperature) and Figure 9 (to $4.3 \mathrm{~V}$ at $60{ }^{\circ} \mathrm{C}$ ). Under the mild charge-discharge condition (to $4.3 \mathrm{~V}$ at room temperature) in Figure 8a, the discharge capacities of the Sn-incorporated samples are maintained from the 2nd to 50th cycle, whereas that of the pristine sample continues to decrease slowly. Meanwhile, the discharge capacities of the Sn-incorporated samples also start to decrease at higher charge cutoff voltages, but the degree of capacity decrease of the pristine sample is much higher in Figure $8 b$,c. Increasing charge cutoff voltage for high capacity would incur structural instability owing to excessive Li-ion extraction [28]. Because the incorporation of Sn strengthens the cathode active material particles as evidenced by the higher breaking strength value, the Sn-incorporated samples can maintain the stability of the crystal structure and have enhanced cycling performance over the pristine sample. Regarding the effect of operating temperature, a high temperature causes the degradation of cycle performance because of electrolyte side reactions [29]. While the discharge capacities of the Sn-incorporated samples at room temperature are maintained (Figure 8a), the high temperature charge-discharge indeed aggravates the cycling performance as shown in Figure 9. However, a trend that the Sn-incorporated samples have improved cycling performance relative to the pristine sample was again observed at high temperatures, which can be attributed to the high breaking strength of the Sn-incorporated samples.
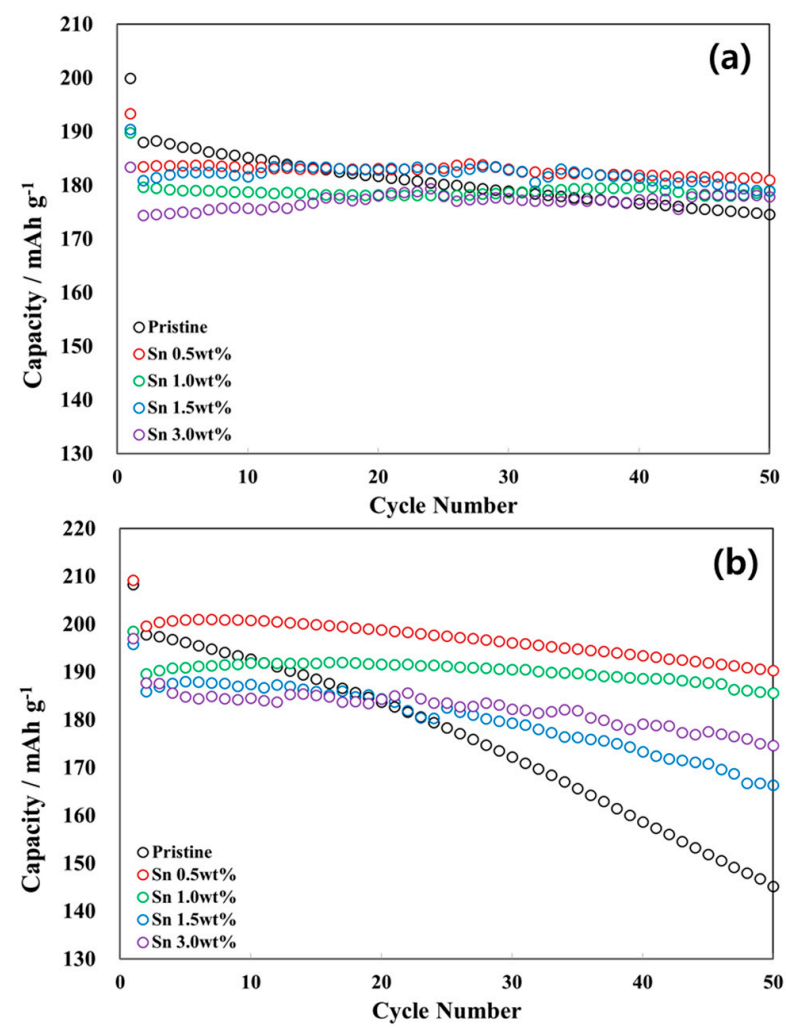

Figure 8. Cont. 


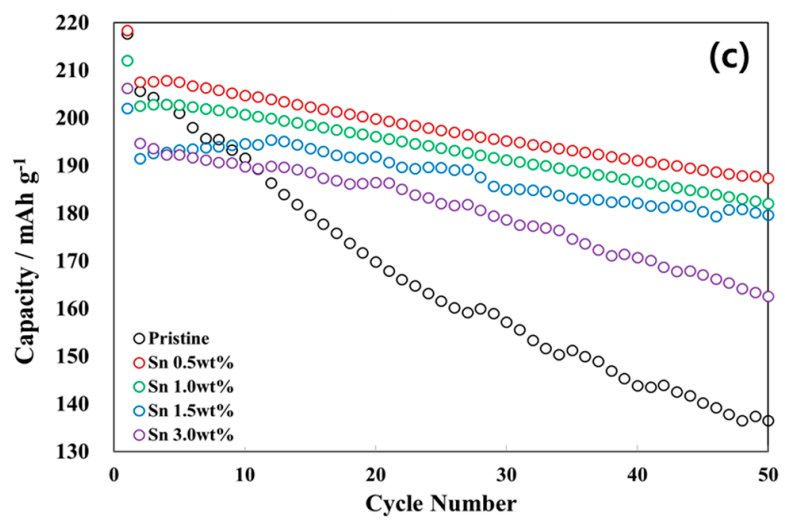

Figure 8. Cycling performance of the cathode active materials at room temperature from 3.0 to (a) 4.3, (b) 4.4 , or (c) $4.5 \mathrm{~V}$ ( $0.1 \mathrm{C}$ for the 1 st cycle and $0.5 \mathrm{C}$ from the 2 nd cycle).

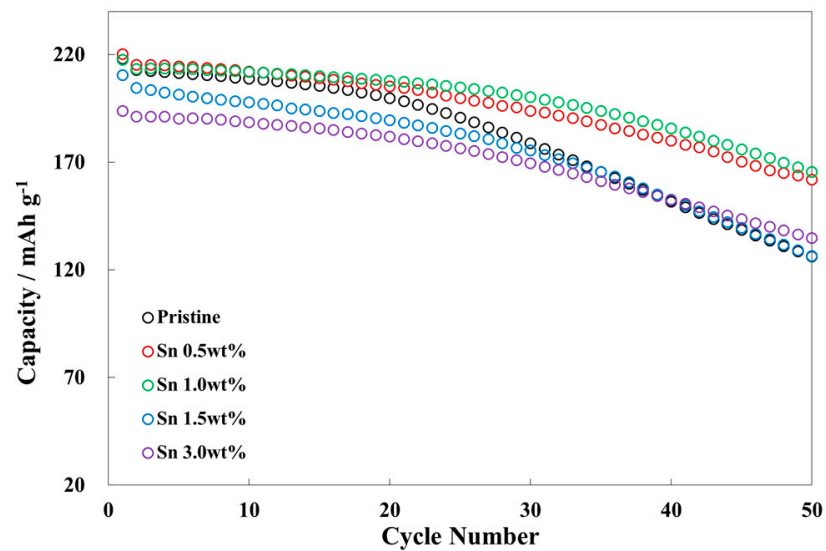

Figure 9. Cycling performance of the cathode active materials at high temperature $\left(60{ }^{\circ} \mathrm{C}\right)$ and $0.5 \mathrm{C}$ ( $0.1 \mathrm{C}$ for the 1 st cycle and $0.5 \mathrm{C}$ from the 2 nd cycle).

\section{Conclusions}

The physicochemical characterizations of Sn-incorporated NCM were conducted using SEM, EDS mapping, XRD, XPS, and the breaking strength of particles. The XRD results demonstrated that the (003) peak tends to shift toward lower angles with increases in Sn content, which is in line with a larger ionic radius of $\mathrm{Sn}^{4+}(0.71 \AA)$ rather than that of $\mathrm{Co}^{3+}(0.62 \AA), \mathrm{Ni}^{2+}(0.69 \AA), \mathrm{Ni}^{3+}(0.56 \AA)$, and $\mathrm{Mn}^{4+}(0.53 \AA)$. The breaking strength of the Sn-incorporated samples is higher than the pristine sample with the highest breaking strength observed at $\mathrm{Sn} 1.0 \mathrm{wt} \%$. While the discharge capacity of the Sn-incorporated samples is slightly decreased compared to the pristine sample, the Sn-incorporated samples have low overpotential compared to the pristine cathode active material at high C-rates. A trend that the Sn-incorporated samples have improved cycling performance relative to the pristine sample was observed, which can be attributed to the high breaking strength of the Sn-incorporated samples.

Supplementary Materials: The following are available online at http:/ /www.mdpi.com/2075-4701/7/10/395/s1, Figure S1: SEM cross-section images of the cathode active materials; Figure S2: EDS cross-section mapping of the cathode active materials: (a) pristine, (b) Sn $0.5 \mathrm{wt} \%$, (c) Sn $1.0 \mathrm{wt} \%$, and (d) Sn $1.5 \mathrm{wt} \%$; Figure S3: Wide XPS of the cathode active materials.

Acknowledgments: This study was supported by the R\&D Center for Valuable Recycling (Global-Top R\&BD Program) of the Ministry of Environment. Junho Song was supported by a grant from the Fundamental R\&D Program for Technology of World Premier Materials funded by the Ministry of Knowledge Economy, Republic of Korea (Project number: 10037921). 
Author Contributions: Ga-hee Kang and Junho Song conceived and designed the experiments; Ga-hee Kang performed the experiments and analyzed the data; Ko-woon Lee provided technical support; Ga-hee Kang and Kyungjung Kwon co-wrote the paper.

Conflicts of Interest: The authors declare no conflict of interest. The founding sponsors had no role in the design of the study; in the collection, analyses, or interpretation of data; in the writing of the manuscript; or in the decision to publish the results.

\section{References}

1. Tarascon, J.M.; Armand, M. Issues and challenges facing rechargeable lithium batteries. Nature 2010, 414, 359-367. [CrossRef] [PubMed]

2. Chen, X.P.; Zhou, T.; Kong, J.R.; Fang, H.X.; Chen, Y.B. Separation and recovery of metal values from leach liquor of waste lithium nickel cobalt manganese oxide based cathodes. Sep. Purif. Technol. 2015, 141, 76-83. [CrossRef]

3. Cai, G.Q.; Fung, K.Y.; Ng, K.M.; Wibowo, C. Process development for the recycle of spent lithium ion batteries by chemical precipitation. Ind. Eng. Chem. Res. 2014, 53, 18245-18259. [CrossRef]

4. Zou, H.Y.; Gratz, E.; Apelian, D.; Wang, Y. A novel method to recycle mixed cathode materials for lithium ion batteries. Green Chem. 2013, 15, 1183-1191. [CrossRef]

5. Park, C.M.; Kim, J.H.; Kim, H.S.; Sohn, H.J. Li-alloy based anode materials for Li secondary batteries. Chem. Soc. Rev. 2010, 39, 3115-3141. [CrossRef] [PubMed]

6. Chagnes, A.; Pospiech, B. A brief review on hydrometallurgical technologies for recycling spent lithium-ion batteris. J. Chem. Technol. Biotechnol. 2013, 88, 1191-1199. [CrossRef]

7. Kang, J.; Senanayake, G.; Sohn, J.; Shin, S.M. Recovery of cobalt sulfate from spent lithium ion batteries by reductive leaching and solvent extraction with Cyanex 272. Hydrometallurgy 2010, 100, 168-171. [CrossRef]

8. Meshram, P.; Pandey, B.D.; Mabkhand, T.R. Extraction of lithium from primary and secondary sources by pre-treatment, leaching and separation: A comprehensive review. Hydrometallurgy 2014, 150, 192-208. [CrossRef]

9. Ordones, J.; Gago, E.J.; Girard, A. Processes and technologies for the recycling and recovery of spent lithium-ion batteries. Energy Rev. 2016, 60, 195-205.

10. Zeng, X.; Li, J.; Singh, N. Recycling of spent lithium-ion battery: A critical review. Environ. Sci. Technol. 2014, 44, 1129-1165. [CrossRef]

11. Huang, K.; Li, J.; Xu, Z. A novel process for recovering valuable metals from waste nickel-cadmium batteries. Environ. Sci. Technol. 2009, 43, 8974-8978. [CrossRef] [PubMed]

12. Pietrelli, L.; Bellomo, B.; Fontana, D.; Montereali, M. Characterization and leaching of NiCd and NiMH spent batteries for the recovery of metals. Waste Manag. 2005, 25, 221-226. [CrossRef] [PubMed]

13. Ku, H.; Jung, Y.; Jo, M.; Park, S.; Kim, S.; Yang, D.; Rhee, K.; An, E.-M.; Sohn, J.; Kwon, K. Recycling of spent lithium-ion battery cathode materials by ammoniacal leaching. J. Hazard. Mater. 2016, 313, 138-146. [CrossRef] [PubMed]

14. Jha, M.K.; Kumari, A.; Jha, A.K.; Kumar, V.; Hait, J.; Pandey, B.D. Recovery of lithium and cobalt from waste lithium ion batteries of mobile phone. Waste Manag. 2013, 33, 1890-1897. [CrossRef] [PubMed]

15. Lee, C.K.; Rhee, K.I. Reductive leaching of cathodic active materials from lithium ion battery wastes. Hydrometallurgy 2003, 68, 5-10. [CrossRef]

16. Nan, J.M.; Han, D.M.; Yang, M.J.; Cui, M.; Hou, X.L. Recovery of metal values from a mixture of spent lithium-ion batteries and nickel-metal hydride batteries. Hydrometallurgy 2006, 84, 75-80. [CrossRef]

17. Shin, S.M.; Kim, N.H.; Sohn, J.S.; Yang, D.H.; Kim, Y.H. Development of a metal recovery process from Li-ion battery wastes. Hydrometallurgy 2005, 79, 172-181. [CrossRef]

18. Krüger, S.; Hanisch, C.; Kwade, A.; Winter, M.; Nowak, S. Effect of impurities caused by a recycling process on the electrochemical performance of $\mathrm{Li}\left[\mathrm{Ni}_{0.33} \mathrm{Co}_{0.33} \mathrm{Mn}_{0.33}\right] \mathrm{O}_{2}$. J. Electroanal. Chem. 2014, 726, 91-96.

19. Weng, Y.; Xu, S.; Huang, G.; Jiang, C. Synthesis and performance of $\mathrm{Li}\left[\left(\mathrm{Ni}_{1 / 3} \mathrm{Co}_{1 / 3} \mathrm{Mn}_{1 / 3}\right)_{1-x} \mathrm{Mg}_{x}\right] \mathrm{O}_{2}$ prepared from spent lithium ion batteries. J. Hazard. Mater. 2013, 246, 163-172. [CrossRef] [PubMed]

20. Lim, J.M.; Hwang, T.; Kim, D.; Park, M.S.; Cho, K.; Cho, M. Intrinsic origins of crack generation in Ni-rich $\mathrm{LiNi}_{0.8} \mathrm{Co}_{0.1} \mathrm{Mn}_{0.1} \mathrm{O}_{2}$ layered oxide cathode material. Sci. Rep. 2017, 8, 39669. [CrossRef] [PubMed] 
21. Shu, J.; Ma, R.; Shao, L.Y.; Shui, M.; Wu, K.G.; Lao, M.M.; Wang, D.J.; Long, N.B.; Ren, Y.L. In-situ X-ray diffraction study on the structural evolutions of $\mathrm{LiNi}_{0.5} \mathrm{Co}_{0.3} \mathrm{Mn}_{0.2} \mathrm{O}_{2}$ in different working potential windows. J. Power Sources 2014, 245, 7-18. [CrossRef]

22. Chen, Z.; Wang, J.; Chao, D.L.; Baikie, T.; Bai, L.Y.; Chen, S.; Zhao, Y.L.; Sum, T.C.; Lin, J.Y.; Shen, Z.X. Hierarchical porous $\mathrm{LiNi}_{1 / 3} \mathrm{Co}_{1 / 3} \mathrm{Mn}_{1 / 3} \mathrm{O}_{2}$ nano-/micro spherical cathode material: Minimized cation mixing and improved $\mathrm{Li}^{+}$mobility for enhanced electrochemical performance. Sci. Rep. 2016, 6, 25771. [CrossRef] [PubMed]

23. Ma, X.L.; Wang, C.W.; Cheng, J.G.; Sun, J.T. Effects of Sn doping on the structural and electrochemical properties of $\mathrm{LiNi}_{0.8} \mathrm{Co}_{0.2} \mathrm{O}_{2}$ cathode materials. Solid State Ion. 2007, 178, 125-129. [CrossRef]

24. Ren, H.B.; Mu, X.M.; Huang, Y.H.; Li, Z.J.; Wang, Y.H.; Cai, P.; Peng, Z.H.; Zhou, Y.H. Effects of Sn doping on electrochemical characterizations of $\mathrm{Li}\left[\mathrm{Ni}_{1 / 3} \mathrm{Co}_{1 / 3} \mathrm{Mn}_{1 / 3}\right] \mathrm{O}_{2}$ cathode material. Ionics 2010, 16, 497-502. [CrossRef]

25. Zhao, Y.J.; Xia, M.H.; Hu, X.S.; Zhao, Z.K.; Wang, Y.; Lv, Z. Effects of Sn doping on the structural and electrochemical properties of $\mathrm{Li}_{1.2} \mathrm{Ni}_{0.2} \mathrm{Mn}_{0.8} \mathrm{O}_{2}$ Li-rich cathode materials. Electrochim. Acta 2015, 174, 1167-1174. [CrossRef]

26. Jonsen, P.; Haggblad, H.A.; Sommer, K. Tensile strength and fracture energy of pressed metal powder by diametral compression test. Powder Technol. 2007, 176, 148-155. [CrossRef]

27. Araki, K.; Taguchi, N.; Sakaebe, H.; Tatsumi, K.; Ogumi, Z. Electrochemical properties of Li $\mathrm{Ni}_{1 / 3} \mathrm{Co}_{1 / 3} \mathrm{Mn}_{1 / 3} \mathrm{O}_{2}$ cathode material modified by coating with $\mathrm{Al}_{2} \mathrm{O}_{3}$ nanoparticles. J. Power Sources 2014, 269, 236-243. [CrossRef]

28. Zhang, X.H.; Yu, C.; Huang, X.D.; Zheng, J.; Guan, X.F.; Luo, D.; Li, L.P. Novel composites $\mathrm{Li}\left[\mathrm{Li}_{x} \mathrm{Ni}_{0.34-x} \mathrm{Mn}_{0.47} \mathrm{Co}_{0.19}\right] \mathrm{O}_{2}(0.18 \leq x \leq 0.21)$ : Synthesis and application as high-voltage cathode with improved electrochemical performance for lithium ion batteries. J. Mater. Chem. 2012, 81, 233-238. [CrossRef]

29. Darma, M.S.D.; Lang, M.; Kleiner, K.; Mereacre, L.; Liebau, V.; Fauth, F.; Bergfeldt, T.; Ehrenberg, H. The influence of cycling temperature and cycling rate on the phase specific degradation of a positive electrode in lithium ion batteries: A post mortem analysis. J. Power Sources 2016, 327, 714-725. [CrossRef] 